\title{
SIMULASI SISTEM PROSES PRODUKSI DI PT. JAKARTA CAKRATUNGGAL STEEL MILLS
}

\author{
Dyah Lintang Trenggonowati \\ Program Studi Teknik Industri, Universitas Sultan Ageng Tirtayasa \\ e-mail: dyahlintang@untirta.ac.id
}

\begin{abstract}
ABSTRAK
Dalam kegiatan produksi di PT. Jakarta Cakra Tunggal Steel Mills melibatkan berbagai lokasi yang didalamnya terdapat beberapa mesin dengan kapasitas produksi yang berbeda-beda. Pada proses pembuatan besi beton melibatkan beberapa lokasi seperti transfer billet, reheat furnance, roughing, intermediete, finishing, cooling bed, cold shear, packaging dan gudang. Dengan menggunakan software ProModel dibuatlah model simulasi proses produksi besi beton di PT. Jakarta Cakra Tunggal Steel Mills yang sudah diverifikasi dan sudah divalidasi sehingga mampu mewakili sistem nyata. Sebagai analisisnya dilakukan pengembangan simulasi dengan perancangan usulan perbaikan model simulasi. Peneliti merancang 3 usulan perbaikan model simulasi yaitu dengan penambahan 1 buah crane dari packaging ke gudang, dengan penambahan 1 buah mesin finishing dan conveyor 5, dan dengan penambahan 1 buah mesin furnance. Pada usulan perbaikan 1, dilakukan penambahan 1 buah crane dari packaging ke gudang agar mampu meningkatkan hasil produksi. Pada usulan perbaikan 2, dilakukan penambahan 1 buah mesin finishing dan conveyor 5 karena mesin finishing dan conveyor 5 memiliki \% utilitas (kesibukan) yang tinggi pada sistem nyata. Pada usulan perbaikan 3, dilakukan penambahan 1 buah mesin furnance karena mesin furnance memiliki \% utilitas (kesibukan) yang tinggi pada sistem nyata.
\end{abstract}

Kata Kunci: Simulasi Sistem, Software ProModel, Utilitas

\begin{abstract}
Production activities at PT. Jakarta Cakra Steel Steel Mills involve a variety of locations in which there are multiple machines with production capacity varying. In concrete iron-making process involves several locations such as the transfer of billet, reheat furnaces, roughing, intermediete, finishing, cooling bed, cold shear, packaging and warehouse. By using the software ProModel simulation model made of concrete iron production process at PT. Jakarta Cakra Steel Steel Mills that has been verified and validated so as to represent the real system. As the analysis carried out by the design simulation development simulation model proposed improvements. Researchers designed three proposed improvement is the addition of a simulation model crane 1 piece of packaging to the warehouse, with the addition of 1 piece of finishing machines and conveyor 5, and with the addition of 1 fruit machines furnance. In the repair proposal 1, the addition of 1 piece of packaging to warehouse crane in order to raise production. In the proposed improvements 2, the addition of 1 piece of finishing machines and conveyor 5 for finishing machines and conveyor 5 has a\% utility (busyness) is high on the real system. In the proposed improvements 3 , the addition of 1 piece furnance machine because the machine has a\% furnance utilities (busyness) is high on the real system.
\end{abstract}

Keywords: Simulation Systems, Software ProModel, Utilities

\section{PENDAHULUAN}

Pertumbuhan industri-industri di Indonesia baik industri besar, menengah maupun kecil menuntut adanya suatu persaingan antar industri itu sendiri. Kenyataan umum yang terjadi di lapangan, terutama bagi industri kecil dan menengah adalah sering dijumpainya suatu sistem produksi yang diatur seadanya, dimana para pengelola industri tersebut lebih mementingkan pada upaya agar produksi berjalan terus tanpa melalui perhitungan perencanaan produksi yang cukup matang.

PT. Jakarta Cakratunggal Steel Mills adalah salah satu perusahaan pengolahan baja nasional yang memproduksi baja tulangan beton atau yang lebih dikenal masyarakat dengan istilah besi beton. Besi beton merupakan besi yang digunakan untuk penulangan konstruksi beton atau yang lebih dikenal sebagai beton bertulang. Secara umum besi beton tulangan mengacu pada dua bentuk yaitu besi polos (plain bar) dan besi ulir (deformed bar/BJTD). Besi beton yang dihasilkan oleh PT. Jakarta 
Cakratunggal Steel Mills meliputi ukuran 9,3 milimeter hingga 40 milimeter dengan panjang yang telah distandarisasi yaitu 12 meter. Perusahaan ini didirikan pada tahun 1989 di atas lahan seluas 14.8 ha, berlokasi di Jl. Raya Bekasi Km. 21-22 Pulogadung Jakarta, dan mulai beroperasi pada Juni 1992. Pengoprasian perusahaan ini dilakukan dalam tiga tahap, tahap pertama Rolling Mills yang beroperasi pada bulan Juni 1992, tahap kedua Melting Shop pada bulan Desember 1992, dan tahap ketiga Rolling Mills pada bulan Juni 1993. Perusahaan ini menggunakan teknologi semi intergrated mini mills dengan kapasitas produksi billet 420.000 Metric Ton (MT)/tahun dan besi beton sebesar $360.000 \mathrm{MT} /$ tahun.

Menurut Hasan simulasi merupakan suatu model pengambilan keputusan dengan mencontoh atau mempergunakan gambaran sebenarnya dari suatu sistem kehidupan dunia nyata tanpa harus mengalaminya pada keadaan yang sesungguhnya [1]. Simulasi sendiri memungkinkan pembuatan kesimpulan dari solusi-solusi atas percobaan yang ada dan memberikan keputusan-keputusan sehubungan dengan percobaan tersebut sebagai alternatif dalam melakukan pendekatan. Penggunaan simulasi dapat dilakukan pada sistem manufaktur atau produksi, dalam penelitian ini mensimulasikan pembuatan besi beton.

Permasalahan yang terdapat pada proses produksi ini yaitu hasil produksi yang tidak mencapai target. PT. Jakarta Cakra Tunggal Steel Mills memproduksi besi beton sebesar 3.060.234 unit per tahun. Sedangkan permintaan konsumen untuk besi beton sebesar 3.602.000 unit per tahun. Berdasarkan permasalahan yang ada PT. Jakarta Cakra Tunggal Steel Mills tidak mampu memenuhi permintaan konsumennya. Untuk mengurangi masalah tersebut maka diperlukan simulasi. Metode simulasi yang digunakan adalah simulasi dengan menggunakan software Promodel. Promodel merupakan salah satu dari beberapa software simulasi. Software ini merupakan alat desain simulasi dan animasi untuk memodelkan sistem manufaktur. Dengan adanya simulasi ini diharapkan didapatkan cara agar produksi besi beton dapat sesuai rencana dan produksi besi beton meningkat.

\section{Permodelan Sistem}

Menurut Djati dan Bonet S. L. pemodelan suatu sistem adalah suatu proses penyaringan dan penyeleksian yang dilakukan sedemikian rupa terhadap berbagai data sehingga didapatkan beberapa data atau komponen sistem yang dapat dimodelkan, dan yang dianggap kurang penting atau tidak relevan dapat diasumsikan mampu mendukung tujuan yang ingin dicapai [2].

Menurut Turner, Mize, Case dan Nazemetz, sistem dapat dikatakan sebagai kumpulan komponen yang berhubungan dengan beberapa bentuk interaksi yang bekerja bersama-sama dengan tujuan untuk mencapai tujuannya. Suatu sistem dapat terdiri dari sistem-sistem bagian (subsystem). Misalnya, sistem komputer terdiri dari subsistem perangkat keras dan subsistem perangkat lunak. Masing-masing subsistem dapat terdiri dari subsistem-subsistem yang lebih kecil lagi atau terdiri dari komponen-komponen. Subsistem perangkat keras (hardware) dapat terdiri dari alat masukan, alat pemroses, alat keluaran dan simpanan luar [3].

Sedangkan pengertian model adalah sebuah model didefinisikan sebagai representasi dari suatu sistem untuk tujuan pembelajaran terhadap sistem. Dalam memodelkan sebuah sistem sangat penting untuk memahami konsep dari sebuah sistem dan sistem pembatas [4]. Sebuah sistem didefinisikan sebagai sekumpulan objek (manusia, mesin, dan informasi) yang dihubungkan dan saling berinteraksi bersama-sama dalam aturan-aturan atau adanya saling ketergantungan untuk menyelesaikan beberapa tujuan. Dalam pemodelan sistem, sangat penting untuk pembatas antara sistem dan lingkungannya. Model dan sistem merupakan kata kunci dari definisi simulasi, model diartikan sebagai representasi atau perwujudan dari serangkaian obyek atau ide-ide dalam bentuk matematik atau hubungan logika tertentu [5]. Sedangkan sistem adalah sekumpulan elemen atau entitas, yang saling berinteraksi (melakukan aktivitas) untuk mencapai tujuan tertentu, misalnya sistem bank, parkir, lini perakitan dan sebagainya. Adapun kegunaan dari pemodelan sistem adalah antaralain sebagai berikut ini: eksperimen yang 
dilakukan pada sistem secara langsung akan membutuhkan biaya dan usaha yang cukup besar. Waktu yang digunakan untuk percobaan pada model jauh lebih singkat dibandingkan dengan percobaan pada system secara langsung. Dalam uji coba menggunakan model, resiko yang di hadapi akan lebih aman daripada ujicoba langsung pada system sebenarnya. Model dari system dapat digunakan untuk menjelaskan, memahami dan memperbaiki system tersebut. Dapat mengetahui performansi dan informasi dari suatu sistem.

Adapun pengertian model secara harfiah adalah suatu representasi atau formalisasi dalam bahasa tertentu dari suatu sistem nyata. Pemodelan merupakan tahapan dalam membuat model dari suatu sistem nyata. Tujuan dari studi pemodelan adalah menentukan informasi (variabel dan parameter) yang dianggap penting untuk dikumpulkan, sehingga tidak ada model yang unik. Adapun Kriteria model yang baik antara lain: mudah dimengerti pemakainya, harus mempunyai tujuan yang jelas, dinyatakan secara jelas dan lengkap, mudah dikontrol dan dimanipulasi pemakai, mengandung pemecahan masalah yang penting dan jelas, mudah diubah, mempunyai prosedur modifikasi dan Dapat berkembang dari sederhana menuju ke kompleks hubungan model dan sistemnyata

\section{Simulasi Sistem}

Simulasi merupakan salah satu cara untuk memecahkan berbagai persoalan yang dihadapi dunia nyata. Banyak metode yang dibangun dalam Operations Research dan System Analyst untuk kepentingan pengambilan keputusan dengan menggunakan berbagai analisis data. Pendekatan yang digunakan untuk memecahkan berbagai masalah yang tidak pasti dan kemungkinan jangka panjang yang tidak dapat diperhitungkan dengan seksama adalah dengan simulasi.

\section{Simulasi Pro Model}

Promodel (Production Modeler) adalah salah satu perangkat lunak yang dapat digunakan untuk memodelkan berbagai sistem manufaktur dan jasa. Dalam Promodel selama simulasi berlangsung dapat diamati animasi dari kegiatan yang sedang berlangsung dan hasilnya akan ditampilkan dalam bentuk tabel maupun grafik yang memudahkan untuk penganalisisan.

\section{Location}

Dalam Promodel, location merupakan tempat atau layout dari model suatu sistem, yang berisi gambar latar belakang seperti mesin-mesin, stasiun kerja, gudang penyimpanan, dan sebagainya. Lokasi adalah komponen statis sehingga tidak ikut bergerak selama simulasi dijalankan.

\section{Entity}

Entity merupakan sesuatu yang akan menjadi objek yang akan diproses dalam model sistem, seperti: bahan baku, produk setengah jadi (WIP), produk jadi, produk reject, bahkan lembar kerja.

\section{Path Network}

Path Networks merupakan lintasan kerja Resources yang terdiri dari node-node dan lintasan yang menghubungkan antara node yang satu dengan node yang lainnya.

\section{Resources}

Resources merupakan manusia, peralatan atau perlengkapan kerja lainnya yang digunakan/bertugas melakukan pemindahan entity.

\section{Arrivals}

Arrivals menunjukkan tempat atau lokasi dimana entitas tiba pada suatu sistem yang diamati untuk pertama kali.

\section{Processing}

Processing merupakan operasi yang terjadi didalam sistem dan dilakukan pada lokasi dan antar lokasi.

Berdasarkan latar belakang permasalahan, maka rumusan masalahnya adalah bagaimana membuat model simulasi sistem produksi di departemen produksi yang dapat mewakili keadaan yang sebenarnya sehingga dapat menganalisis utilitas sistem proses tersebut dengan menggunakan simulasi.

Adapun tujuan penelitian ini adalah: mengetahui sistem eksisting pada PT. Jakarta Cakratunggal Steel Mills, mengetahui produktivitas sistem eksisting pada PT. Jakarta Cakratunggal Steel Mills, menentukan usulan perbaikan agar target produksi besi beton dapat melebihi target sistem produksi eksisting dan memberikan usulan terbaik pada sistem simulasi yang telah dibuat. 


\section{Pengolahan Data}

\section{METODE PENELITIAN}

Pengolahan data dilakukan dengan menggunakan software Promodel dan SPSS 20.

\section{Penentuan Distribusi}

Pengujian distribusi ini bertujuan untuk mengetahui waktu proses produksi tersebut berdistribusi normal, binomial, eksponensial, poisson, dan distribusi-distribusi lain yang sesuai. Pengujian distribusi menggunakan Stat Fit Promodel. Pengujian ini berguna untuk masing-masing proses produksi pada saat menggunakan simulasi software Promodel.

\section{Simulasi Sistem Nyata}

Pembuatan simulasi proses produksi PT. Jakarta Cakra Tunggal Steel Mills terdapat beberapa hal yang perlu diperhatikan dalam pembuatan model simulasi sistem produksi PT. Jakarta Cakra Tunggal Steel Mills yaitu layout sistem produksi dan waktu proses produksi setiap lokasi. Pembuatan model simulasi proses produksi PT. Jakarta Cakra Tunggal Steel Mills menggunakan software Promodel.

\section{Verifikasi dan Validasi Model}

Tahap verifikasi dan validasi model merupakan suatu tahap analisis untuk membandingkan output hasil produksi sistem nyata dan hasil produksi simulasi. Ada beberapa aspek yang dibandingkan yaitu melihat model animasi, membandingkan dengan sistem nyata atau model simulasi lainnya. Pada tahap validasi dilakukan perhitungan error pada ratarata hasil produksi dan standar deviasi.

\section{Usulan Perbaikan Model}

Usulan perbaikan dilakukan untuk mengetahui apakah hasil produksi mampu melebihi target produksi model eksisting atau tidak.

\section{Uji Anova}

Uji beda ini dilakukan untuk mengetahui rata-rata sampel output produk pada sistem produksi nyata memiliki perbedaan yang signifikan atau tidak dengan output produksi yag dihasilkan dengan simulasi Promodel. Uji beda tersebut menggunakan software SPSS.

Berikut ini merupakan flow chart penelitian di PT. Jakarta Cakra Tunggal Steel mills.

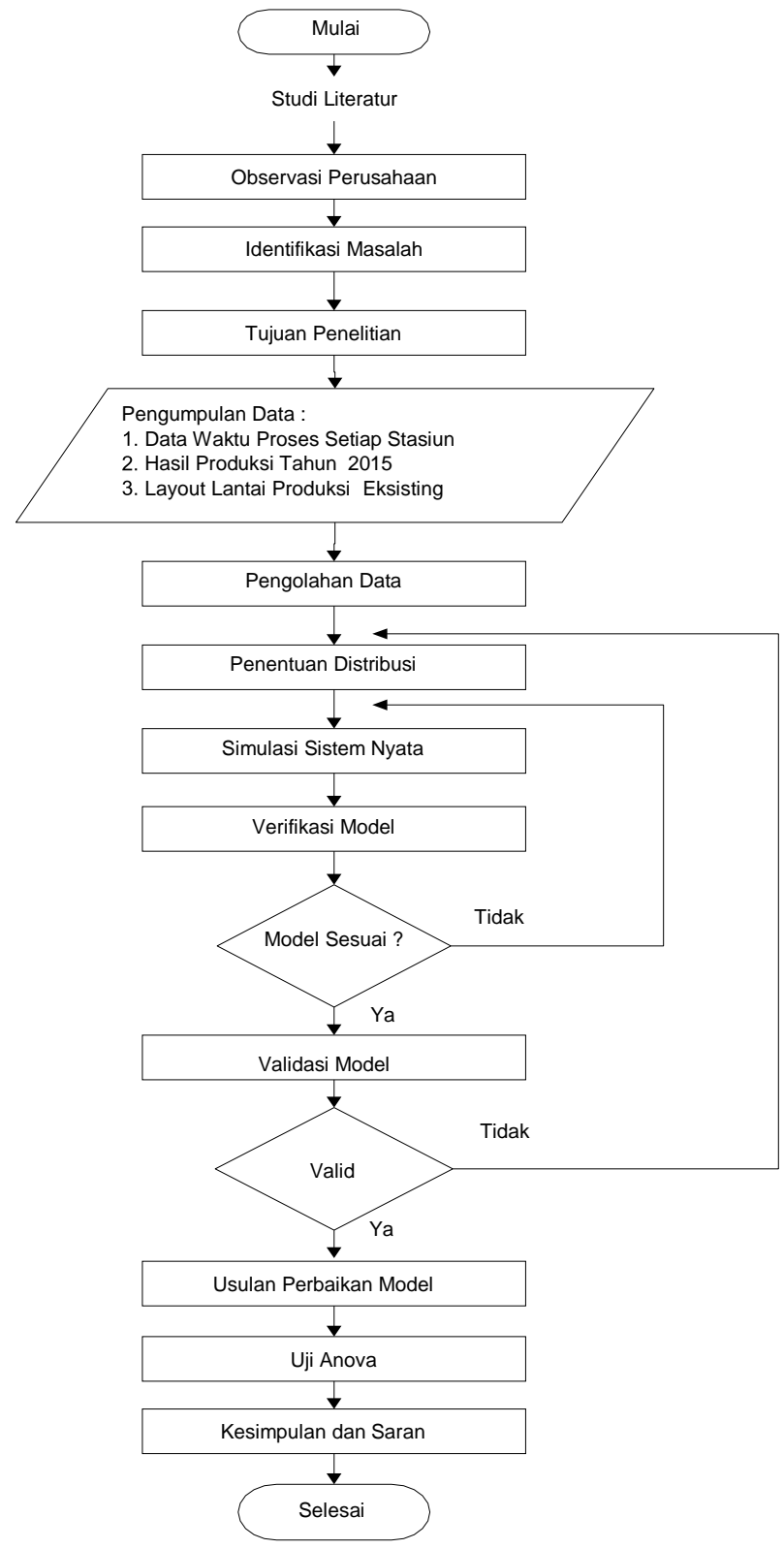

Gambar 1. Flow Chart

\section{HASIL DAN PEMBAHASAN}

Uji Statistika

Distribusi statistik waktu antar kedatangan entitas dan lama waktu proses tiap mesin diperoleh dengan melakukan uji distribusi statistika menggunakan perangkat lunak Promodel 7.5. Uji statistika yang dilakukan yaitu:

\section{Uji statistika deskriptif}

Pada statistika deskriptif dapat diketahui informasi-informasi terkait suatu data seperti jumlah data, nilai minimum dan maksimum dari suatu data, nilai rata-rata, nilai tengah, modus, standar deviasi, hingga variansi dari suatu data. 


\section{Uji korelasi}

Uji korelasi merupakan metode statistik yang digunakan untuk mengukur besarnya hubungan linier antara dua variabel atau lebih. Sehingga pada uji ini didapatkan hasil suatu data bersifat independen atau dependen. Data bersifat independen (berada pada 2 sisi) yang artinya adalah data tersebut bebas dan saling menyebar sehingga dapat dikatakan tidak berkorelasi.

\section{Uji scatter plot}

Scatter Plot adalah suatu diagram yang menunjukan penyebaran suatu data. Output yang didapatkan pada uji scatter plot yaitu data saling menyebar atau tidak. Data saling menyebar yang artinya data bersifat independen. Hal ini menunjukkan bahwa data waktu tersebut tidak saling berhubungan sehingga baik untuk dilakukan pada uji statistika selanjutnya.

\section{Uji run test}

Run Test merupakan statistika non parametrik yang bisa digunakan untuk menguji pada kasus satu sampel. Berdasarkan uji run test didapatkan output yaitu jumlah data waktu antar kedatangan, titik di atas median, titik dibawah median, total run, rata-rata runs, standar deviasi runs, statistik runs, tingkat signifikansi dan p-value. Dalam runs test turning points didapatkan output yaitu jumlah data, turning points, rata-rata turnings, standar deviasi, statistik turnings, tingkat signifikansi, statistik turnings dan p-value. P-value dibandingkan dengan nilai alfa, jika $p$ value $>$ alfa maka data yang dihasilkan adalah $d o$ not reject begitupun sebaliknya jika $p$ value $<$ alfa maka data yang dihasilkan adalah reject.

\section{Uji estimasi parameter}

Estimasi parameter atau disebut juga Auto fit dalam software promodel 7.5 merupakan estimasi atau praduga dari nilai parameter populasi berdasarkan data yang didapat. Output dari uji estimasi parameter adalah rank dan acceptance dari uji statistika sebelumnya. Dari hasil rank maka diambil distribusi yang memiliki rank tertinggi.

\section{Uji goodness of fit}

Uji goodness of fit merupakan pengujian kecocokan atau kebaikan antara hasil pengamatan (frekuensi pengamatan) tertentu dengan frekuensi yang diperoleh berdasarkan nilai harapannya (frekuensi teoritis). Fungsi goodness of fit untuk mengetahui apakah distribusi yang sudah ditentukan dalam auto fit sudah tepat dengan data waktu proses tersebut atau belum.

Berikut ini merupakan hasil akhir uji statistika waktu antar kedatangan entitas dan lama waktu proses tiap mesin pada model eksisting:

Data waktu transfer billet berdistribusi normal dengan mean sebesar 556,63 dan standar deviasi sebesar 11,61 detik. Data waktu proses di reheat furnance 2 jam. Data waktu proses roughing berdistribusi normal dengan mean sebesar 126,3 dan standar deviasi sebesar 2,246. Data waktu proses intermediete stand berdistribusi normal dengan mean sebesar 75,8 dan standar deviasi sebesar 2,89 detik. Data waktu proses finishing berdistribusi lognormal dengan mean sebesar 70,57 dan standar deviasi sebesar 1,786 detik. Data waktu proses cooling bed berdistribusi normal dengan mean 609,8 dan standar deviasi sebesar 10,028 detik. Data waktu proses cold shear stand berdistribusi uniform dengan mean sebesar 93,73 dan half range sebesar 6 detik.

Data waktu proses packaging berdistribusi lognormal dengan mean sebesar 22,83 dan standar deviasi sebesar 3,71 detik.

\section{Pengembangan Model Model Eksisting}

Model simulasi dibuat dengan bantuan software ProModel 7,5. Model simulasi yang berhasil dibangun dapat dilihat pada Gambar 2.

Berdasarkan Gambar 2, layout model eksisting terdiri dari 9 stasiun yang terdiri dari transfer billet, furnance, roughing stand, intermediet stand, finishing stand, cooling bed, cold shear, packaging dan gudang serta terdiri dari 7 conveyor. Proses awal sistem adalah billet dengan panjang 8,74 meter dimasukkan ke transfer billet. Billet yang berasal dari transfer billet dibawa oleh conveyor 1 (36,736 feet) ke reheat furnance. Reheat furnance memiliki kapasitas untuk menampung 110 billet. Di reheat furnance, billet di gabungkan sementara sebanyak 4 batch. Lalu billet yang 


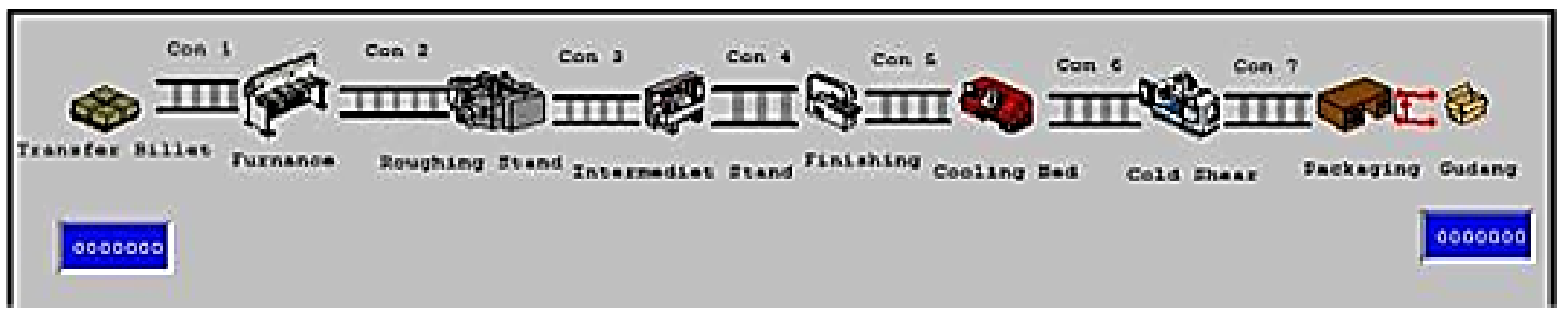

Gambar 2. Model Simulasi Sistem Nyata (Eksisting)

Tabel 1. Replikasi Model Eksiting

\begin{tabular}{ccccccc}
\hline No & $\mathrm{X}_{\mathrm{i}}$ & $\bar{X}$ & $(\mathrm{Xi}-\bar{X})^{2}$ & $\mathrm{~S}$ & Error & N' $^{\prime}$ \\
\hline 1 & 373050 & & 225 & & & \\
2 & 373025 & & 100 & & & \\
3 & 373050 & & 225 & & & \\
4 & 373025 & & 100 & & & \\
5 & 373025 & 373035 & 100 & 16,67 & 119,22 & 2,74 \\
6 & 373050 & & 225 & & & \\
7 & 373025 & & 100 & & & \\
8 & 373025 & & 100 & & & \\
9 & 373025 & & 100 & & & \\
10 & 373050 & & 225 & & & \\
\hline
\end{tabular}

telah dijadikan batch dipisahkan kembali. Billet dibawa oleh conveyor 2 (40,56 feet) ke roughing. Roughing memiliki kapasitas untuk menampung 1 billet. Lalu billet dibawa oleh conveyor 3 (37,865 feet) ke intermediete stand. Intermediete stand memiliki kapasitas untuk menampung 1 billet. Di intermediete stand, billet di potong menjadi 12 potong. Lalu billet yang telah dipotong dibawa oleh conveyor 4 (40,237 feet) ke finishing. Finishing memiliki kapasitas untuk menampung 1 billet. Lalu billet dibawa oleh conveyor 5 (36,736 feet) ke cooling bed. Cooling bed memiliki kapasitas untuk menampung 40 batch billet. Di cooling bed, billet digabungkan sementara sebanyak 40 batch. Lalu billet yang telah dijadikan batch dipisahkan kembali dan billet dibawa oleh conveyor 6 (39,43 feet) ke cold shear. Cold shear memiliki kapasitas untuk menampung 1 billet. Di cold shear, billet di potong menjadi 25 potong. Lalu billet yang telah di potong di bawa oleh conveyor 7 (40,46 feet) ke packaging. Di packaging, billet digabungkan secara permanen menjadi 1 gulungan yang berisi 25 unit besi beton. Lalu, gulungan billet dari packaging dibawa oleh crane ke gudang dengan kecepatan 150,150 fpm.

Berdasarkan hasil simulasi dengan menggunakan software promodel 7,5 diperoleh hasil output simulasi dengan menggunakan 10 replikasi. Replikasi 1 sebesar 373050, replikasi 2 sebesar 373025, replikasi 3 sebesar 373025, replikasi 4 sebesar 373000, replikasi 5 sebesar 373025, replikasi 6 sebesar 373050, replikasi 7 sebesar 373025, replikasi 8 sebesar 373025, replikasi 9 sebesar 373000 , dan replikasi 10 sebesar 373025. Sehingga diperoleh hasil ratarata output sistem eksisting sebesar 373025.

\section{Replikasi}

Replikasi digunakan untuk mengetahui nilai rata-rata output dari model simulasi. Cara untuk mengetahui berapa jumlah replikasi yang dibutuhkan agar dapat mencapai suatu Confidence Interval (CI) atau tingkat kesalahan yang diinginkan maka perlu dilakukan running simulasi terlebih dahulu dengan replikasi awal sejumlah 5-10 kali. Pada penelitian ini, replikasi yang digunakan sebanyak 10 replikasi.

Berikut ini merupakan hasil perhitungan rekapitulasi model eksisting pembuatan besi beton ukuran S13 dengan 10 replikasi menggunakan software ProModel 7,5.

Berdasarkan hasil perhitungan, diperoleh nilai N' sebesar 2,74 sedangkan $\mathrm{N}=10$ replikasi, sehingga $N(10)>N^{\prime}(2,74)$ maka data yang telah disimulasikan dapat dikatakan cukup dan tidak diperlukan penambahan replikasi lagi.

\section{Validas Model}

Proses translasi dari kondisi sistem nyata 
ke model konseptual selalu melibatkan unsur kesalahan, karenanya perlu proses verifikasi dan validasi model untuk mereduksi atau mengeliminasi kesalahan. Proses verifikasi digunakan untuk membangun model dengan benar (Building the Right Model) sedangkan proses validasi bertujuan untuk membangun model yang benar (Building the Right Model). Bagaimana mengukur kesesuaian antara sistem nyata dengan model simulasi. Ujung Pelaksanaan validasi pada dasarnya paralel dengan simulasi awal artinya data yang didapatkan digunakan untuk simulasi awal dan proses validasi.

Proses validasi menguji hasil output simulasi dibandingkan dengan data riil di lapangan yang diambil secara random, dengan statistik dibandingkan rata-rata dan deviasi standar. Dengan demikian, uji hipotesis perbandingan simulasi dalam sistem dilakukan dengan menguji persaman:

$\mathrm{H}_{0}$ : Tidak ada perbedaan yang signifikan antar model existing dengan model usulan perbaikan.

$\mathrm{H}_{1}$ : Ada perbedaan yang signifikan antar nodel existing dengan model usulan perbaikan.

Tabel 2. Paired Samples Statistics

\begin{tabular}{ccccc}
\hline & Mean & $N$ & $\begin{array}{c}\text { Std. } \\
\text { Deviation }\end{array}$ & Std. Error \\
\hline $\begin{array}{c}\text { Simulasi } \\
\text { Pair 1 }\end{array}$ & 373025 & 10 & 16,67 & 5,27 \\
Nyata & 306023,4 & 10 & 233406,44 & 73809,60 \\
\hline
\end{tabular}

Berdasarkan Tabel 2 dapat diketahui bahwa jumlah data yang digunakan pada sistem simulasi dan sistem nyata sebanyak 10 . Pada sistem simulasi didapatkan mean sebesar 373025 dengan standar deviasi sebesar 16,67, dan standar error mean sebesar 5,27 sedangkan pada sistem nyata didapatkan mean sebesar 306023,4, dengan standar deviasi sebesar 233406,44, dan standar error mean sebesar 73809,60 .

Tabel 3. Paired Samples Correlations

\begin{tabular}{cccc}
\hline & $\mathrm{N}$ & Correlation & Sig. \\
\hline Simulasi \& Nyata & 10 & .294 & .410 \\
\hline
\end{tabular}

bahwa sistem simulasi dan nyata memiliki nilai korelasi sebesar 0,294 dan nilai signifikan sebesar 0,410. Korelasi antara hasil sistem simulasi dan nyata memiliki korelasi yang kuat karena nilai korelasi yang dihasilkan bernilai positif.

Berdasarkan Tabel 4 didapatkan hasil sistem simulasi dan sistem nyata memiliki nilai mean sebesar 67001,60 standar deviasi sebesar 233401,54 standar error mean 73808,05 tingkat keyakinan 95\% dengan nilai batas bawah (lower) sebesar -99963,80 dan nilai batas atas (upper) sebesar 233967,00. Dari hasil uji paired t-test menggunakan SPSS 20, maka dapat disimpulkan bahwa $\mathrm{H}_{0}$ diterima karena niai $\mathrm{t}_{\text {hitung }}<\mathrm{t}_{\text {tabel }}$ yaitu $0,908<2,262$. Selain itu, nilai signifikan 2-tailed 0,388 lebih besar dari 0,05. Maka nilai $t_{\text {hitung }}$ berada di daerah penerimaan maka model valid.

\section{Perancangan Usulan Model}

Perancangan usulan model usulan dilakukan dengan cara memodifikasi model nyata. Ada 3 usulan perbaikan model simulasi yaitu pertama dengan penambahan 1 buah crane dari packaging ke gudang, kedua dengan penambahan 1 buah mesin finishing dan conveyor 5 , dan ketiga dengan penambahan 1 buah mesin furnance.

\section{Analisis Usulan Perbaikan 1}

Penambahan output dilakukan dengan menambahkan 1 buah crane. Penambahan 1 buah crane dari packaging menuju gudang berguna untuk meningkatkan hasil produksi gulungan besi beton karena dalam prosesnya masih terdapat gulungan yang tidak terangkut dengan efektif jika hanya menggunakan 1 crane dan dapat dilihat pada hasil output simulasi bahwa entitas gulungan masih banyak terdapat dalam sistem. Berikut ini Gambar 4 merupakan gambar layout usulan perbaikan 1.

Berdasarkan Gambar 4, layout usulan perbaikan 1 terdiri dari 9 stasiun yang terdiri dari transfer billet, furnance, roughing stand, intermediet stand, finishing stand, cooling bed, cold shear, packaging dan gudang serta terdiri dari 7 conveyor

Berdasarkan Tabel 3 dapat diketahui 
Tabel 4. Paired Samples Test

\begin{tabular}{|c|c|c|c|c|c|c|c|c|c|}
\hline & & \multicolumn{5}{|c|}{ Paired Difference } & \multirow{3}{*}{$t$} & \multirow{3}{*}{$d f$} & \multirow{3}{*}{ Sig. (2-tailed) } \\
\hline & & \multirow{2}{*}{ Mean } & \multirow{2}{*}{$\begin{array}{c}\text { Std. } \\
\text { Deviation }\end{array}$} & \multirow{2}{*}{ Error Mean } & \multicolumn{2}{|c|}{$\begin{array}{l}\text { 95\% Confidence } \\
\text { Interval of the }\end{array}$} & & & \\
\hline & & & & & Lower & Upper & & & \\
\hline Pair 1 & $\begin{array}{c}\text { Simulasi } \\
\text { Nvata }\end{array}$ & 67001,60 & 233401,54 & 73808,05 & 99963,80 & 233967,00 & 908 & 9 & ,388 \\
\hline
\end{tabular}

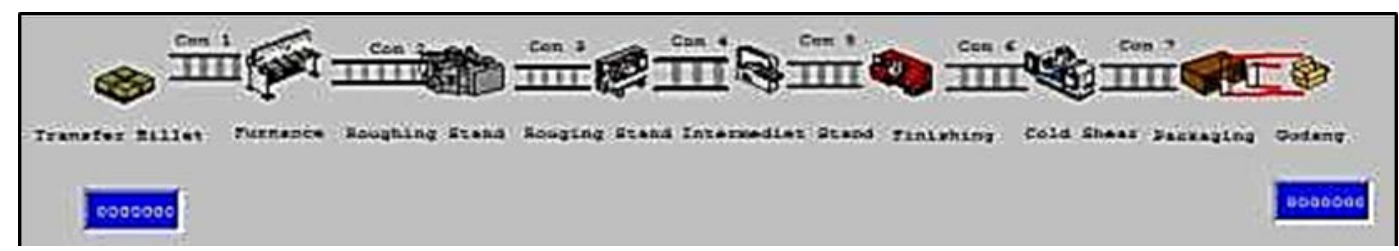

Gambar 4. Layout Usulan Perbaikan 1

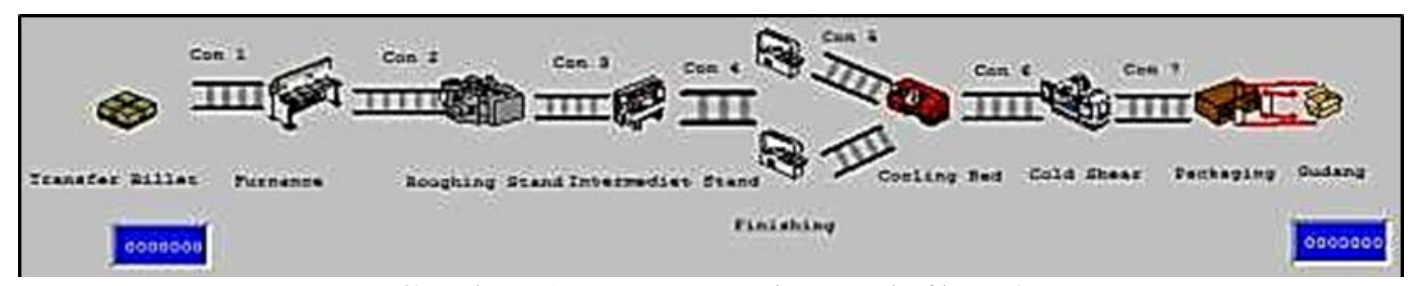

Gambar 5. Layout Usulan Perbaikan 2

Setelah dilakukan penambahan 1 buah crane, diperoleh hasil output simulasi besi beton dengan menggunakan 10 replikasi yaitu replikasi 1 sebesar 596850, replikasi 2 sebesar 596825, replikasi 3 sebesar 596825, replikasi 4 sebesar 596800, replikasi 5 sebesar 596825, replikasi 6 sebesar 596850, replikasi 7 sebesar 596825, replikasi 8 sebesar 596825, replikasi 9 sebesar 596775, dan replikasi 10 sebesar 596825. Sehingga pada usuan perbaikan 1, diperoleh hasil output simulasi rata-rata sebesar 596823. Hasil output simulasi usulan perbaikan 1 memiliki peningkatan dibandingkan dengan hasil output simulasi sistem nyata.

\section{Analisis Usulan Perbaikan 2}

Penambahan output dilakukan dengan penambahan 1 buah mesin finishing dan conveyor 5. Penambahan 1 buah mesin finishing dan conveyor 5 dikarenakan memiliki \% utilitas (kesibukan) yang tinggi pada hasil simulasi Promodel sistem nyata. Utilitas pada finishing sebesar 99,63\% dan conveyor 5 memiliki utilitas 192,06\%. Berikut ini Gambar 5 merupakan gambar layout usulan perbaikan 2 .

Berdasarkan Gambar 5, layout usulan perbaikan 2 terdiri dari 9 stasiun yang terdiri dari transfer billet, furnance, roughing stand, intermediet stand, 2 buah finishing stand, cooling bed, cold shear, packaging dan gudang serta terdiri dari 8 conveyor.

Setelah dilakukan penambahan 1 buah mesin finishing dan conveyor 5, diperoleh hasil output simulasi besi beton dengan menggunakan 10 replikasi yaitu replikasi 1 sebesar 597175, replikasi 2 sebesar 597150, replikasi 3 sebesar 597200, replikasi 4 sebesar 597150, replikasi 5 sebesar 597150, replikasi 6 sebesar 597150, replikasi 7 sebesar 597175, replikasi 8 sebesar 597150, replikasi 9 sebesar 597150, dan replikasi 10 sebesar 597100. Sehingga pada usuan perbaikan 2, diperoleh hasil output simulasi rata-rata sebesar 597155. Hasil output simulasi usulan perbaikan 2 memiliki peningkatan dibandingkan dengan hasil output simulasi sistem nyata.

\section{Analisis Usulan Perbaikan 3}

Penambahan output dilakukan dengan penambahan 1 buah mesin furnance. Penambahan 1 buah mesin furnance dikarenakan memiliki \% utilitas (kesibukan) yang tinggi pada hasil simulasi Promodel sistem nyata yaitu sebesar 97,53\%. Berikut ini merupakan gambar layout usulan perbaikan 3.

Berdasarkan gambar di atas, layout usulan perbaikan 3 terdiri dari 9 stasiun yang terdiri dari transfer billet, 2 buah furnance, roughing 


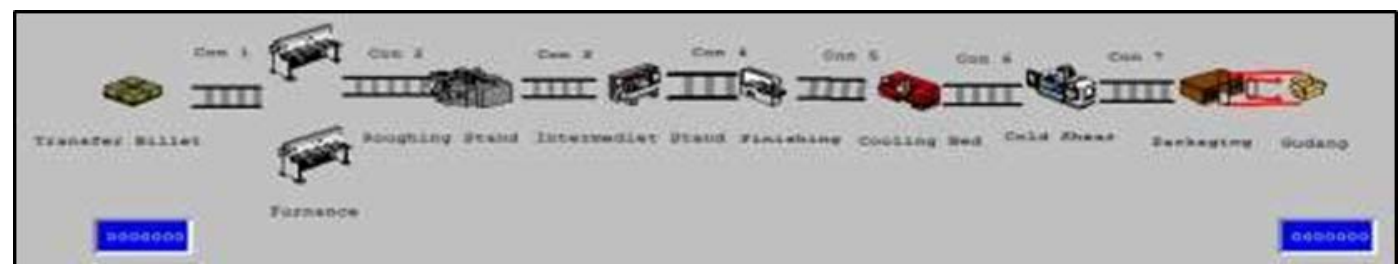

Gambar 6. Layout Usulan Perbaikan 3

stand, intermediet stand, finishing stand, cooling bed, cold shear, packaging dan gudang serta terdiri dari 7 conveyor.

Setelah dilakukan penambahan 1 buah mesin furnance, diperoleh hasil output simulasi besi beton dengan menggunakan 10 replikasi yaitu replikasi 1 sebesar 596450, replikasi 2 sebesar 596425, replikasi 3 sebesar 596475, replikasi 4 sebesar 596450, replikasi 5 sebesar 596450, replikasi 6 sebesar 596425, replikasi 7 sebesar 596425, replikasi 8 sebesar 596475, replikasi 9 sebesar 596450, dan replikasi 10 sebesar 596450. Sehingga pada usuan perbaikan 3, diperoleh hasil output simulasi rata-rata sebesar 596448. Hasil output simulasi usulan perbaikan 3 memiliki peningkatan dibandingkan dengan hasil output simulasi sistem nyata.

\section{Uji Anova}

Uji anova merupakan uji rataan dari $\mathrm{k}$ populasi/perlakuan. Jika dalam pengujian ANOVA hipotesis nol ditolak, maka dilakukan uji pasca ANOVA. Salah satu uji pasca ANOVA yang digunakan adalah uji Fisher's
Least Significant Difference.

H0 : Tidak ada perbedaan yang signifikan antar model eksistingdengan model usulan perbaikan.

$\mathrm{H}$ : Ada perbedaan yang signifikan antar model eksistingdengan model usulan perbaikan.

Tabel 5 merupakan hasil output dari sistem eksisting, usulan perbaikan 1 , usulan perbaikan 2 dan usulan perbaikan 3. Hasil output tersebut di uji menggunakan Uji ANOVA, hasilnya diperoleh seperti ditunjukan pada Tabel 6.

Berdasarkan perhitungan ANOVA menggunakan software SPSS yang telah dilakukan diperoleh nilai $F_{\text {hitung }}$ sebesar 83914223,276 sementara nilai dari $F_{\text {hitung }}$ adalah 2,886, sehingga kesimpulannya adalah tolak $\mathrm{H}_{0}$ atau terima $\mathrm{H}_{1}$, dapat diartikan ada perbedaan yang signifikan dari kondisi eksisting, usulan perbaikan 1, usulan perbaikan 2, usulan perbaikan 3.

Tabel 5. Perhitugan ANOVA

\begin{tabular}{|c|c|c|c|c|}
\hline No & 1 & 2 & 3 & 4 \\
\hline Replikasi & Eksisting & Usulan Perbaikan 1 & Usulan Perbaikan 2 & Usulan Perbaikan 3 \\
\hline 1 & 373050 & 596850 & 597175 & 596450 \\
\hline 2 & 373025 & 596825 & 597150 & 596425 \\
\hline 3 & 373025 & 596825 & 597200 & 596475 \\
\hline 4 & 373000 & 596800 & 597150 & 596450 \\
\hline 5 & 373025 & 596825 & 597150 & 596450 \\
\hline 6 & 373050 & 596850 & 597150 & 596425 \\
\hline 7 & 373025 & 596825 & 597175 & 596425 \\
\hline 8 & 373025 & 596825 & 597150 & 596475 \\
\hline 9 & 373000 & 596775 & 597150 & 596450 \\
\hline 10 & 373025 & 596825 & 597100 & 596450 \\
\hline$\overline{\bar{X}}$ & 373025 & 596823 & 597155 & 596448 \\
\hline $\mathrm{Y}_{\mathrm{ijk}}$ & 1391476508750 & 3561970969375 & 3565940946250 & 3557496205625 \\
\hline
\end{tabular}


Tabel 6. ANOVA SPSS

\begin{tabular}{lrrccc}
\hline \multicolumn{7}{c}{ ANOVA } & F & Sig. \\
\hline Finish_Product & Sum of Squares & Df & Mean Square & & \\
\hline Between Groups & 375594857875 & 3 & 125198285958,33 & 283914223.28 & .000 \\
Within Groups & 15875 & 36 & 440,972 & & \\
\hline Total & 375594873750 & 39 & & & \\
\hline
\end{tabular}

Tabel 8. Perbandingan Mean Different Tiap Usulan Perbaikan

\begin{tabular}{cc}
\hline Alternatif & Mean Different \\
\hline Usulan perbaikan 1 & 596823 \\
Usulan perbaikan 2 & 597155 \\
Usulan perbaikan 3 & 596448 \\
\hline
\end{tabular}

Setelah pengujian ANOVA, kemudian dilakukan perhitungan LSD. Dan hasil akhir LSD menyatakan perbandingan mean different antara usulan perbaikan adalah seperti pada Tabel 8.

Maka berdasarkan perhitungan uji ANOVA dan LSD (Least Significant Difference) maka dipilih alternative terbaik yaitu pada usulan perbaikan 2 karena memiliki mean different terbesar. Yang mana dalam usulan perbaikan 2 adalah penambahan mesin finishing sebanyak 1 buah dan penambahan conveyor 5 sebanyak 1 buah.

\section{KESIMPULAN}

Berdasarkan hasil penelitian yang telah dilakukan pada produk besi beton ukuran 13 di PT. Jakarta Cakra Tunggal Steel Mills, dapat disimpulkan sebagai berikut: sistem eksisting pada PT. Jakarta Cakratunggal Steel Mills terdiri dari 1 transfer billet, 1 mesin reheat furnance, 1 mesin roughing stand, 1 mesin intermediete stand, 1 mesin cooling bed, 1 mesin cold shear, dan 1 packaging dan memiliki 7 conveyor. Data waktu transfer billet berdistribusi normal dengan mean sebesar 556,63 dan standar deviasi sebesar 11,61 detik. Data waktu proses di-reheat furnance 2 jam. Data waktu proses intermediete stand berdistribusi normal dengan mean sebesar 75,8 dan standar deviasi sebesar 2,89 detik. Data waktu proses finishing berdistribusi lognormal dengan mean sebesar 70,57 dan standar deviasi sebesar 1,786 detik. Data waktu proses cooling bed berdistribusi normal dengan mean 609,8 dan standar deviasi sebesar 10,028 detik. Data waktu proses cold shear stand berdistribusi uniform dengan mean sebesar 93,73 dan half range sebesar 6 detik. Data waktu proses packaging berdistribusi lognormal dengan mean sebesar 22,83 dan standar deviasi sebesar 3,71 detik. Produktivitas sistem eksisting PT. Jakarta Cakra Tunggal Steel Mills pada replikasi 1 sebesar 373.050, pada replikasi 2 sebesar 373.025, pada replikasi 3 sebesar 373.050, pada replikasi 4 sebesar 373.025, pada replikasi 5 sebesar 373.025, pada replikasi 6 sebesar 373.050, pada replikasi 7 sebesar 373.025, pada replikasi 8 sebesar 373.025, pada replikasi 9 sebesar 373.025 , dan pada replikasi 10 sebesar 373.050. Usulan yang dapat dilakukan untuk meningkatkan produktivitas besi beton pada usulan perbaikan 1 yaitu menambah crane, pada usulan perbaikan 2 yaitu menambah mesin finishing dan menambah conveyor 5 menjadi 2 buah dan pada usulan perbaikan 3 yaitu menambah mesin furnance. Dari hasil simulasi, jumlah produksi optimal terdapat pada usulan ke 2 karena menghasilkan jumlah total exit terbesar pada activity entity. Pada replikasi 1 sebesar 597.175, pada replikasi 2 sebesar 597.150, pada replikasi 3 sebesar 597.200, pada replikasi 4 sebesar 597.150, pada replikasi 5 sebesar 597.150, pada replikasi 6 sebesar 597.150, pada replikasi 7 sebesar 597.175, pada replikasi 8 sebesar 597.150, pada replikasi 9 sebesar 597.150, dan pada replikasi 10 sebesar 597.100.

\section{DAFTAR PUSTAKA}

[1]. Hasan, M. Iqbal, 2002, Poko-Pokok Materi: Teori Pengambilan Keputusan, Ghalia Indonesia, Jakarta.

[2]. Djati, dan B. S. L., 2007, Simulasi, Teori dan Aplikasinya Yogyakarta: Penerbit ANDI. 
[3]. Turner, W.C., Mize, J.H., Case, K.E., Nazemetz, J.W., 1993, Pengantar Teknik dan Sistem Industri.Surabaya. Penerbit: Guna Widya.

[4]. Arifin, Miftahol, 2008, Simulasi Sistem Industri, Yogyakarta: Graha Ilmu.

[5]. Simatupang, Togar M., 1995, Pemodelan Sistem, Klaten, Penerbit Nindita. 